\title{
Back Pain and Schoolbags among Adolescents in Abha City, Southwestern Saudi Arabia
}

 \\ and Medhat Shalaby ${ }^{1,5}$ \\ 1 Department of Internal Medicine, College of Medicine, King Khalid University, Abha 61421, Saudi Arabia; \\ aassiri@yahoo.com (A.A.); medhatshalaby57@gmail.com (M.S.) \\ 2 Department of Family and Community Medicine, College of Medicine, King Khalid University, \\ Abha 61421, Saudi Arabia; njgirgis@yahoo.co.uk (N.J.A.); drzizous2000@yahoo.com (A.Y.A.) \\ 3 Department of Epidemiology, High Institute of Public Health, Alexandria University, \\ Alexandria 21511, Egypt \\ 4 Department of Community Medicine, College of Medicine Mansoura University, \\ Dakahlia Governorate 35516, Egypt \\ 5 Department of Rheumatology, Faculty of Medicine, Al Azhar University, Cairo 11651, Egypt \\ * Correspondence: mahfouz2005@gmail.com; Tel.: +966-17-241-7629; Fax: +966-17-241-7771
}

Received: 29 October 2019; Accepted: 14 December 2019; Published: 18 December 2019

check for updates

\begin{abstract}
The incorrect carriage of schoolbags and heavy bags may result in back pain (BP) in adolescents. Our objective was to assess the problem of BP and associated factors among adolescents. This was a cross-sectional study targeting intermediate and secondary school adolescents in Abha City, Saudi Arabia. An anonymous questionnaire for BP was used. Student body weight and the weight of their full schoolbag were measured. The study included 876 adolescents. An overall prevalence of BP of $39.4 \%$ (95\% CI: 35.3-43.7) was found. Upper BP (UBP), middle BP (MBP), and lower BP (LBP) amounted to $14.5 \%, 13.4 \%$, and $11.5 \%$, respectively. Associated significant factors with MBP were carrying the bag on one side compared to on the back (adjusted odds ratio $(\mathrm{aOR})=2.13,95 \% \mathrm{CI}: 1.20-3.73)$ and being at intermediate level compared to secondary $(\mathrm{aOR}=1.56$, 95\% CI: 1.04-2.40). On the other hand, gender and schoolbag weight/body weight percent were not found to be significantly associated with MBP. None of the studied factors were significantly associated with overall BP, UBP, or LBP. BP is a prevalent among adolescents in southwest Saudi Arabia. One-sided schoolbag carriage is a significant associated factor for middle back pain. Parents and teachers should encourage students to consider the correct way to carry schoolbag.
\end{abstract}

Keywords: back pain; adolescents; schoolbags; Saudi Arabia

\section{Introduction}

Carrying schoolbags and attending school for a considerable period of time is a scheduled daily activity for adolescents. Recently, the relationship between carrying schoolbags and back pain (BP) has received considerable attention. The incorrect carriage of schoolbags, and carrying heavy bags, may result in back pain in adolescents [1-3].

It is recommended that the weight of the full schoolbag should not exceed $10 \%-15 \%$ of body weight [4]. This is justified by the physiological and biomechanical impacts of carrying heavy schoolbags [4]. However, this limit is often exceeded. Reports from different regions in the world reveal that a considerable proportion of school children carry schoolbags exceeding $20 \%$ of their body weight [5-7]. 
Moreover, previous studies have shown that the schoolbag carriage method is also related to back pain. A bag carried on one side is associated with more back pain than wearing a two-shouldered bag $[8,9]$.

Studies have reported that the prevalence of back pain in school children ranges from $25 \%$ to $55 \%$ in those aged between 10 and 15 years $[1,10,11]$. Back pain in adolescents is an important issue because it increases the risk of having chronic back pain in adulthood [12].

In Saudi Arabia, particularly the southwest region, the extent of back pain problems and their relationship with schoolbag weight and carriage method among school adolescents has not been fully settled. Therefore, the objectives of the present study were to assess the problem of back pain among school adolescents, explore schoolbag weight as a percentage of body weight, find a new optimal cutoff point that indicates BP, identify the methods of carrying schoolbags, and to correlate back pain with these factors.

\section{Materials and Methods}

\subsection{Design}

This was a cross-sectional study.

\subsection{Target Population}

The target population was intermediate and secondary school age adolescents in Abha City, Aseer Region, Southwestern Saudi Arabia. The intermediate and secondary levels in Saudi Arabia include students in grades 7 to 9 and 10 to 12, respectively. The students' ages range from 13-15 years at the intermediate level and 16-18 years at the secondary level.

\subsection{Sample Size Determination and Sampling Technique}

Using the WHO Manual for Sample Size Determination in Health Studies [13], with a conservative anticipated proportion of back pain of 52.2\% among school children in Riyadh [14] and absolute precision of $2 \%$ at the $95 \%$ confidence interval, the minimum sample size required for the study was calculated to be 600 adolescents. A multistage stratified proportional cluster random sample method was followed to select the study population. The stratification factors taken into consideration were the relative number of students in intermediate and secondary schools, male/female differences, and the district in which they lived. The students were recruited from 13 intermediate and secondary schools in Abha city. Within each school, one class was selected randomly from each of the three grades (7-9 and 10-12).

\subsection{Questionnaire Interview}

An anonymous paper-based questionnaire was distributed to each student in their own classroom. The questionnaire included personal and demographic data, and preferred method of schoolbag carriage (any side or always on the back). Back pain (BP) was assessed using the following question: "During the past three months have you felt any pain or ache in the back area for a long time at school, which has lasted for one day or longer?" The response options were "yes", "no", or "I don't know". The last option was regarded as "no". Students positive to back pain were asked to indicate the exact site of the pain (upper, middle, or lower).

\subsection{Adolescent Weight and Schoolbag Weight Measurements}

The adolescent's weight was taken while the student was standing erect without shoes and with minimal clothing. The weight of the student's full schoolbag was measured in kilograms. Bag weight/body weight percent was computed. All measurements were taken by trained examiners. 


\subsection{Funding and Ethical Approval}

The research proposal was revised and accepted by the ethical committee of King Khalid University (received 9 March 2014). Written consent was obtained from the students' parents. Students omitted from the study were those absent on the day of the visit or those with a parental request to not participate in the study.

\subsection{Data Analysis}

Data were analyzed using SPSS. Chi square test was used as a test of significance at $5 \%$ level. Prevalence rates were calculated with concomitant 95\% confidence intervals (95\% CIs).

A receiver operating characteristic (ROC) curve was constructed to examine the predictive performance of schoolbag load as a percent of body weight in identifying children with back pain (overall, upper, middle, and lower). The graphical plot demonstrated the performance of the cutoff points in terms of sensitivity versus 1-specificity. The area under the curve (AUC) is a measure of the accuracy of a test or cutoff point. The AUC value lies between 0.5 and 1, where less than 0.6 denotes a poor classifier and 1 denotes an excellent classifier.

To study the factors associated with BP, multivariable binary logistic regression analysis was used. Adjusted odds ratio (aOR) and the concomitant $95 \%$ CI were computed. Variables included in the model were gender, level (intermediate or secondary), schoolbag carriage method (on the back or on one side) and bag weight/body weight percent.

\section{Results}

\subsection{Description of the Study Sample}

The study included 876 adolescents who were students in intermediate $(439,50.1 \%)$ and secondary schools $(437,49.9 \%)$. The sample comprised 471 males (53.8\%) and 405 females $(46.2 \%)$. Their age ranged from 13 to 19 years with a mean of $15.88 \pm 1.76$ years and a median of 16 years. Regarding fathers' education, $39.5 \%$ (346) were university educated and $27.9 \%$ were educated at the secondary level (244). Regarding mothers' education, the majority were educated to less than secondary level $(49.4 \%, 433)$ and $23.2 \%$ were secondary level educated (203).

\subsection{Prevalence of $B P$}

This study revealed that 345 students reported having BP, giving an overall prevalence of $39.4 \%$ (95\% CI: 35.3-43.7). Among those having BP, 182 (47.2\%) reported having pain at school and 149 $(43.2 \%)$ reported increase in pain when carrying heavy objects. Only 31 students $(9.0 \%)$ asked for medical consultations.

Table 1 shows that the prevalence of upper back pain (UBP) amounted to $14.5 \%$ (95\% CI: 12.1-17.2). Similarly, the prevalence of middle back pain (MBP) amounted to $13.4 \%$ (95\% CI: $11.1-15.5)$, and the prevalence of lower back pain (LBP) was $11.5 \%$ (95\% CI: 9.4-13.9).

Table 1. Prevalence of back pain among the study sample of school adolescents $(n=876)$.

\begin{tabular}{ccc}
\hline Back Pain & No. & Prevalence \% (95\% CI) \\
\hline Overall back pain & 345 & $39.4(35.4-43.7)$ \\
Upper back pain & 127 & $14.5(12.1-17.2)$ \\
Middle back pain & 117 & $13.4(11.1-15.5)$ \\
Lower back pain & 101 & $11.5(9.4-13.9)$ \\
\hline
\end{tabular}




\subsection{Prediction of BP by Schoolbag Weight/Student Body Weight Percent}

Table 2 shows ROC curve analysis of the discrimination of schoolbag weight/body weight percent for back pain. The ability of schoolbag weight/body weight percent, expressed as a continuous variable, to discriminate between those with and without overall, upper, middle, and lower back pain was poor (AUC < 0.6). The corresponding AUC values were 0.501, 0.570, 0.521, and 0.564, respectively. Based on these results, ROC analysis failed to identify new optimal cutoff points.

Table 2. Result of receiver operating characteristic (ROC) for schoolbag weight/student body weight percent to identify back pain.

\begin{tabular}{ccccc}
\hline Back Pain & AUC (95\% CI) & $\begin{array}{c}\text { Optimal Cutoff Point of } \\
\text { Bag wt./Body wt. \% }\end{array}$ & $\begin{array}{c}\text { Sensitivity } \\
\text { (\%) }\end{array}$ & $\begin{array}{c}\text { Specificity } \\
\text { (\%) }\end{array}$ \\
\hline Overall & $0.501(0.467-0.535)$ & $8.65 \%$ & 53.62 & 53.62 \\
Upper back pain & $0.570(0.5-0.603)$ & $8.50 \%$ & 60.63 & 51.50 \\
Middle back pain & $0.521(0.4-0.554)$ & $10.0 \%$ & 70.9 & 37.55 \\
Lower back pain & $0.564(0.5-0.597)$ & $8.43 \%$ & 62.38 & 54.19 \\
\hline
\end{tabular}

AUC: Area under the curve; 95\% CI: 95\% confidence interval.

\subsection{Characteristics of the Students' Schoolbags}

Table 3 shows the characteristics of students' schoolbags. The weight of a full schoolbag ranged from 1 to $10.5 \mathrm{~kg}$ with an average of $4.97 \pm 1.60 \mathrm{~kg}$ and a median of $4.9 \mathrm{~kg}$. The average weight of the bags was not statistically different $(p=0.623)$ among intermediate students $(4.95 \pm 1.41)$ compared to secondary students $(5.00 \pm 1.77)$. Schoolbag weight/body weight percent of the study sample ranged from $3.22 \%$ to $16.8 \%$ with an average of $9.14 \% \pm 4.9 \%$ and a median of $8.6 \%$. Regarding the distribution of schoolbag weight/body weight percent by level, the frequency of students with a value of $\geq 10 \%$ was higher among intermediate- $(42.6 \%)$ than secondary-level students $(31.6 \%)$. The distribution was statistically significant $(p=0.001)$. This cutoff point was based on the literature. Regarding schoolbag carriage methods, most of the intermediate students carried their bag on their backs $(254,57.9 \%)$, compared to $21.7 \%$ (95) in secondary-level students. The difference was statistically significant $(p=0.001)$.

Table 3. Characteristics of students' schoolbags.

\begin{tabular}{ccccc}
\hline & \multicolumn{2}{c}{ Level } & \multirow{2}{*}{ Total } & \multirow{2}{*}{-Value } \\
\cline { 2 - 3 } & Intermediate & Secondary & & \\
\hline Schoolbag's full weight $(\mathrm{kg})$ & $4.95 \pm 1.41$ & $5.00 \pm 1.77$ & $4.97 \pm 1.60$ & 0.623 \\
\hline $\begin{array}{c}\text { Schoolbag }(\mathrm{kg}) / \text { body weight }(\mathrm{kg}) \%: \\
<10\end{array}$ & $252(57.4 \%)$ & $299(68.4 \%)$ & $551(62.9 \%)$ & 0.001 \\
$\geq 10$ & $187(42.6 \%)$ & $138(31.6 \%)$ & $325(37.1 \%)$ & \\
\hline $\begin{array}{c}\text { Schoolbag carriage method: } \\
\text { on back } \\
\text { on one side }\end{array}$ & $254(57.9 \%)$ & $95(21.7 \%)$ & $349(39.8 \%)$ & 0.001 \\
\hline
\end{tabular}

\subsection{Factors Associated with BP}

Table 4 shows multivariable analysis of potential factors associated with back pain among the study sample of school adolescents. Regarding MBP, intermediate-school adolescents had significantly higher probability of having pain ( $\mathrm{aOR}=1.56,95 \% \mathrm{CI}$ : $1.04-2.40$ ) compared to secondary school adolescents. Similarly, students carrying bags on one side had significantly higher probability of having MBP $(\mathrm{aOR}=2.13,95 \%$ CI: 1.20-3.73) compared to students who carried bags on their back. On the other hand, gender and schoolbag weight/body weight percent were not found to be significantly associated with MBP. 
The study showed that none of the studied factors were found to be significantly associated with overall BP, UBP, or LBP.

Table 4. Multivariable analysis for factors associated with back pain among the study sample of school adolescents $(\mathrm{n}=876)$.

\begin{tabular}{|c|c|c|c|c|}
\hline & Overall Back Pain & Upper Back Pain & Middle Back Pain & Lower Back Pain \\
\hline & aOR $(95 \% \mathrm{CI})$ & aOR $(95 \% \mathrm{CI})$ & aOR $(95 \% \mathrm{CI})$ & aOR (95\% CI) \\
\hline $\begin{array}{l}\text { Sex: males } \\
\text { females }\end{array}$ & $\begin{array}{c}\text { Ref } \\
0.87(0.60-1.27)\end{array}$ & $\begin{array}{c}\text { Ref } \\
1.32(0.79-2.20)\end{array}$ & $\begin{array}{c}\text { Ref } \\
0.91(0.53-1.54)\end{array}$ & $\begin{array}{c}\text { Ref } \\
0.57(0.32-1.04)\end{array}$ \\
\hline $\begin{array}{l}\text { Level: secondary } \\
\text { intermediate }\end{array}$ & $\begin{array}{c}\text { Ref } \\
1.08(0.80-1.46)\end{array}$ & $\begin{array}{c}\text { Ref } \\
0.73(0.48-1.12)\end{array}$ & $\begin{array}{c}\text { Ref } \\
1.56(1.04-2.40)\end{array}$ & $\begin{array}{c}\text { Ref } \\
1.05(0.66-1.67)\end{array}$ \\
\hline $\begin{array}{l}\text { Method of carriage: } \\
\text { on the back } \\
\text { on one side }\end{array}$ & $\begin{array}{c}\text { Ref } \\
1.20(0.82-1.74)\end{array}$ & $\begin{array}{c}\text { Ref } \\
0.81(0.49-1.35)\end{array}$ & $\begin{array}{c}\text { Ref } \\
2.13(1.20-3.73)\end{array}$ & $\begin{array}{c}\text { Ref } \\
0.89(0.49-1.61)\end{array}$ \\
\hline $\begin{array}{c}\text { Schoolbag }(\mathrm{kg}) / \text { body } \\
\text { weight }(\mathrm{kg}) \% \text { : } \\
<10 \\
\geq 10\end{array}$ & $\begin{array}{c}\text { Ref } \\
1.00(0.75-1.40)\end{array}$ & $\begin{array}{c}\text { Ref } \\
1.45(0.98-2.14)\end{array}$ & $\begin{array}{c}\text { Ref } \\
0.81(0.53-1.25)\end{array}$ & $\begin{array}{c}\text { Ref } \\
0.77(0.50-1.23)\end{array}$ \\
\hline
\end{tabular}

\section{Discussion}

Emerging data suggest that back pain in adolescents is responsible for a substantial disability burden and consumes considerable healthcare services. Of further concern is the fact that back pain during this period of life may have health implications in adulthood. Although the enormous disability burden of back pain in adults is well documented, the consequences of the condition in children are not so well acknowledged [15]. The attitude toward back pain in children and adolescents has undergone a large change in the past 15-20 years. Report of back pain in childhood was previously considered rare, and a sign of serious underlying pathology. In fact, several clinical practice guidelines include "age under 20 years" as a red flag for back pain assessment [16]. However, more recent studies have indicated that the condition is common, and it is usually not possible to diagnose a specific patho-anatomical cause for the pain [17].

The present study reported a prevalence rate of back pain (BP) of $39.4 \%$ among adolescents. Figures for UBP, MBP, and LBP were $14.5 \%, 13.4 \%$, and $11.5 \%$, respectively. A systematic review reported wide ranges of prevalence estimates of back pain due to differences in study population, definition of back pain, study design, and prevalence period. Point prevalence estimates ranged from $3 \%$ to $39 \%$ [15]. A recent study among Nigerian adolescents reported an overall BP prevalence of $17 \%$. The corresponding figures for UBP, MBP, and LBP were $19 \%, 15 \%$, and $25 \%$, respectively [18]. In Tunisia, a figure of $32 \%$ of BP was reported among secondary school students [19]. Similarly, a figure of $32.1 \%$ was found in a recent study in Iran [20]. In Sweden, a figure of $44.7 \%$ was reported [21]. In Spain, a figure of 39.8\% for LBP was reported [22]. In Saudi Arabia, a recent study reported a figure of $31.9 \%$ for LBP among adolescents [23].

A recent systematic review revised important associated factors related to BP among adolescents. The identified associated factors were gender, age, weight, posture, and schoolbag [15]. The present study addressed the following associated factors: gender, level (as a proxy for age), and schoolbag.

The present study showed that gender was not significantly associated with back pain among adolescents. A study in Australia showed that adolescent girls appear to be at higher risk of reporting back pain than boys [24]. Another study in Nigeria showed that gender was not associated with BP among secondary-school adolescents [25]. The role of gender in BP showed inconsistency in systematic reviews [15].

The results of the present study revealed that school students were mostly used to carrying schoolbags on one side (60.2\%). However, this finding is not in agreement with the results of other studies $[1,6,26,27]$, which reported that most students carried their schoolbags over two shoulders. 
Moreover, this finding is not in accordance with the guidelines for the safe carriage of schoolbags. Most organizations' guidelines encourage the use of both backpack straps to carry the schoolbag [28,29]. The results of the present study reveal a significant relationship between the schoolbag carriage method and the prevalence of middle back pain (MBP). The risk of MBP was significantly higher among students who carried their schoolbag on one side. This finding is in agreement with the results of other studies [1,5,30-32]. It seems that carrying the schoolbag on two shoulders helps to maintain a correct posture and reduce the risk of back pain among students. With regards to the one-side carriage method, studies have indicated that students who carry their schoolbag on one side foster lateral curvature of the spine, impaired posture, and consequently, increased probability of musculoskeletal pain $[31,33]$.

In the present study, the average schoolbag weight was $4.97 \pm 1.60 \mathrm{~kg}$ and the average relative weight was $9.14 \% \pm 4.9 \%$. These figures indicate that the study students are carrying lighter schoolbags compared to corresponding students in other Saudi studies [3,6]. Additionally, only $37.1 \%$ of the study students were carrying more than the weight-limit recommendation for schoolbag use in children ( $10 \%$ of their body weight) [34]. This result was less than figures reported in Jeddah (75.9\%) [6] and Al-Ahsa, Saudi Arabia (72.4\%) [3].

There is controversy regarding the contributory role of relative schoolbag weight to back pain. It has been described as a risk factor for back pain by some studies [35,36]. However, more recent studies suggest no association between schoolbag weight and back pain or discomfort [11,37]. The present study found no evidence to support the role of heavy schoolbags ( $>10 \%$ of body weight) in developing back pain. This finding may suggest that the standard weight limit should be reviewed. The current study attempted to review the safe threshold limit of schoolbag weight and its discriminative power to identify back pain by conducting ROC curve analysis. According to the results of the ROC curve analysis, it was apparent that the ability of the relative schoolbag weight to predict back pain at different sites is poor for different cutoff points. These results are similar to the finding of a previous study [38], which reported that relative schoolbag weight alone is not enough as a guideline for safe schoolbag weight. Other factors should be taken into consideration along with relative weight, including carrying duration and method [38-40]. In addition, other studies suggest that schoolbag weight limits should take student age [41] and sex [42] into consideration.

\section{Conclusions}

Back pain is a prevalent problem among school-going adolescents in southwest Saudi Arabia. Most students carried their schoolbags on one side. One-sided carriage is a significant risk factor for middle back pain. Parents and teachers should encourage students to consider the correct schoolbag carriage. There is not sufficient evidence that the relative schoolbag weight alone is a predictive factor for back pain among school-going adolescents. Therefore, it is recommended that upcoming studies should consider the multifactorial etiology of back pain in adolescents. Future research should also take into account the person who packed the schoolbag (the child or the mother), whether it is packed for one day or the whole week, and the method of transportation to school (public transport, walking, biking, or parents' car). Guidelines for safe schoolbags should be taken into consideration along with relative schoolbag weight and other factors such as student's age and sex, as well as carrying duration and method.

Author Contributions: Funding acquisition and project supervision, A.A.; Conceptualization, A.A., A.A.M., N.J.A., M.S.; Methodology, M.S., N.J.A., A.Y.A.; formal analysis, A.A.M., A.Y.A., N.J.A.; investigation, M.S., N.J.A., A.Y.A.; original draft preparation, A.A.M., N.J.A., review and editing, A.A., A.A.M., N.J.A. All authors have read and agreed to the published version of the manuscript.

Funding: The research was supported by a grant provided by King Abdel Aziz City for Science and Technology (34-444), Saudi Arabia.

Acknowledgments: We would like to acknowledge the schools and students who participated in this study. We would also like to thank the research assistants who participated in data collection.

Conflicts of Interest: The authors declare no conflict of interest. 


\section{References}

1. Spiteri, K.; Busuttil, M.-L.; Aquilina, S.; Gauci, D.; Camilleri, E.; Grech, V. Schoolbags and back pain in children between 8 and 13 years: A national study. Br. J. Pain 2017, 11, 81-86. [CrossRef] [PubMed]

2. De Paula, A.; Silva, J.; Paschoarelli, L.C.; Fujii, J. Backpacks and school children's obesity: Challenges for public health and ergonomics. Work 2012, 41 (Suppl. 1), 900-906. [CrossRef] [PubMed]

3. Al-Saleem, S.A.; Ali, A.; Ali, S.I.; Alshamrani, A.A.; Almulhem, A.M.; Al-Hashem, M.H. A study of school bag weight and back pain among primary school children in Al-Ahsa, Saudi Arabia. Epidemiology (SunnyvaleCalif.) 2016, 6, 222. [CrossRef] [PubMed]

4. Cardon, G.; Balague, F. Are children's backpack weight limits enough? A critical review of the relevant literature. Spine 2005, 30, 1106. [CrossRef] [PubMed]

5. Al-Hazzaa, H. How much load do Saudi school boys carry on their shoulder. Saudi Med. J. 2006, 27, 1567-1571.

6. Al Shahry, F.S.; Almahmoud, H.A.; Alhujairy, R.I.; Aljohi, K.K. Effect of school bags on body mechanics among Saudi children. Biosci. Biotechnol. Res. Commun. 2018, 11, 402-408. [CrossRef]

7. Barbosa, J.; Marques, M.C.; Izquierdo, M.; Neiva, H.P.; Barbosa, T.M.; Ramirez-Velez, R.; Alonso-Martinez, A.M.; Garcia-Hermoso, A.; Aguado-Jimenez, R.; Marinho, D.A. Schoolbag weight carriage in Portuguese children and adolescents: A cross-sectional study comparing possible influencing factors. BMC Pediatrics 2019, $19,157$. [CrossRef]

8. Talbott, N.R.; Bhattacharya, A.; Davis, K.G.; Shukla, R.; Levin, L. School backpacks: It's more than just a weight problem. Work 2009, 34, 481-494. [CrossRef]

9. Noll, M.; Candotti, C.T.; Rosa, B.N.; Loss, J.F. Back pain prevalence and associated factors in children and adolescents: An epidemiological population study. Rev. Saude Publica 2016, 50, 31. [CrossRef]

10. Aartun, E.; Hartvigsen, J.; Wedderkopp, N.; Hestbaek, L. Spinal pain in adolescents: Prevalence, incidence, and course: A school-based two-year prospective cohort study in 1300 Danes aged 11-13. BMC Musculoskelet. Disord. 2014, 15, 187. [CrossRef]

11. Oka, G.A.; Ranade, A.S.; Kulkarni, A.A. Back pain and school bag weight-A study on Indian children and review of literature. J. Pediatric Orthop. B 2019, 28, 397-404. [CrossRef]

12. Wirth, B.; Humphreys, B.K. Pain characteristics of adolescent spinal pain. BMC Pediatrics 2015, 15, 42. [CrossRef] [PubMed]

13. Lwanga, S.K.; Lemeshow, S. Sample Size Determination in Health Studies: A Practical Manual; World Health Organization: Geneva, Switzerland, 1991.

14. Alghadir, A.H.; Gabr, S.A.; Al-Eisa, E.S. Mechanical factors and vitamin D deficiency in schoolchildren with low back pain: Biochemical and cross-sectional survey analysis. J. Pain Res. 2017, 10, 855. [CrossRef] [PubMed]

15. Kamper, S.J.; Yamato, T.P.; Williams, C.M. The prevalence, risk factors, prognosis and treatment for back pain in children and adolescents: An overview of systematic reviews. Best Pract. Res. Clin. Rheumatol. 2016, 30, 1021-1036. [CrossRef] [PubMed]

16. Verhagen, A.P.; Downie, A.; Popal, N.; Maher, C.; Koes, B.W. Red flags presented in current low back pain guidelines: A review. Eur. Spine J. 2016, 25, 2788-2802. [CrossRef] [PubMed]

17. Cieply, R.; Milbrandt, T. Back pain in children and adolescents. Curr. Orthop. Pract. 2009, 20, 627-633. [CrossRef]

18. Ayanniyi, O.; Mbada, C.E.; Muolokwu, C.A. Prevalence and profile of back pain in Nigerian adolescents. Med. Princ. Pract. 2011, 20,368-373. [CrossRef]

19. Ben Ayed, H.; Yaich, S.; Trigui, M.; Ben Hmida, M.; Ben Jemaa, M.; Ammar, A.; Jedidi, J.; Karray, R.; Feki, H.; Mejdoub, Y. Prevalence, Risk Factors and Outcomes of Neck, Shoulders and Low-Back Pain in Secondary-School Children. J. Res. Health Sci. 2019, 19, e00440.

20. Noormohammadpour, P.; Borghei, A.; Mirzaei, S.; Mansournia, M.A.; Ghayour-Najafabadi, M.; Kordi, M.; Kordi, R. The Risk Factors of Low Back Pain in Female High School Students. Spine 2019, 44, E357-E365. [CrossRef] 
21. Sundell, C.G.; Bergström, E.; Larsén, K. Low back pain and associated disability in Swedish adolescents. Scand. J. Med. Sci. Sports 2019, 29, 393-399. [CrossRef]

22. Pellisé, F.; Balagué, F.; Rajmil, L.; Cedraschi, C.; Aguirre, M.; Fontecha, C.G.; Pasarín, M.; Ferrer, M. Prevalence of low back pain and its effect on health-related quality of life in adolescents. Arch. Pediatrics Adolesc. Med. 2009, 163, 65-71. [CrossRef] [PubMed]

23. Alanzi, M.S.Z.; Almuhawwis, A.; Ghannam, A.; Abo el-Fetoh, N.M.; Alsahli, F.A.A.; Almalki, M.A.M.; Alenezi, T.M.A.; Alruwaili, F.M.M.; Alenezi, A.T.; Alanazey, M.A.M. Low Back Pain in Population of Arar City, Northern Saudi Arabia: An Epidemiological Study. Egypt. J. Hosp. Med. 2017, 69, 2839-2845. [CrossRef]

24. Grimmer, K.; Williams, M. Gender-age environmental associates of adolescent low back pain. Appl. Ergon. 2000, 31, 343-360. [CrossRef]

25. Adegoke, B.O.; Odole, A.C.; Adeyinka, A.A. Adolescent low back pain among secondary school students in Ibadan, Nigeria. Afr. Health Sci. 2015, 15, 429-437. [CrossRef] [PubMed]

26. Natasha, A.A.; Syukri, A.A.; Diana, M.K.S.N.; Ima-Nirwana, S.; Chin, K.-Y. The association between backpack use and low back pain among pre-university students: A pilot study. J. Taibah Univ. Med. Sci. 2018, 13, 205-209.

27. Alghamdi, R.S.; Nafee, H.M.; El-Sayed, A.; Alsaadi, S.M. A study of school bag weight and back pain among intermediate female students in Dammam City, Kingdom of Saudi Arabia. J. Nurs. Educ. Pract. 2018, 8, 3. [CrossRef]

28. Rateau, M.R. Use of backpacks in children and adolescents: A potential contributor of back pain. Orthop. Nurs. 2004, 23, 101-105. [CrossRef]

29. AAP. American Academy of Pediatrics: Back to School Tips on Getting the Year Off to a Good Start-From the American Academy of Pediatrics. Available online: https://www.aap.org/en-us/about-the-aap/aappress-room/news-features-and-safety-tips/Pages/Back-to-School-Tips-Getting-the-Year-Off-to-a-GoodStart-from-the-AAP.aspx (accessed on 1 October 2019).

30. Dianat, I.; Karimi, M.A. Association of parental awareness of using schoolbags with musculoskeletal symptoms and carrying habits of schoolchildren. J. Sch. Nurs. 2014, 30, 440-447. [CrossRef]

31. Ozgül, B.; Akalan, N.E.; Kuchimov, S.; Uygur, F.; Temelli, Y.; Polat, M.G. Effects of unilateral backpack carriage on biomechanics of gait in adolescents: A kinematic analysis. Acta Orthop. Traumatol. Turc. 2012, 46, 269-274. [CrossRef]

32. Patil, M.; Sumana, S.; Shagale, N. Awareness of parents about characteristics and carrying habits of backpacks and its comparison with behavioural practices of their children. Int. J. Pediat. Res. 2016, 3, 173-179.

33. Dockrell, S.; Kane, C.; O'keefe, E. Schoolbag weight and the effects of schoolbag carriage on secondary school students. Ergonomics 2006, 9, 216-222.

34. Lavigne, V.R. Weight limit recommendation in backpack use for school-aged children. J. Clin. Chirop. Pediatr. 2014, 14, 1156-1159.

35. Whittfield, J.; Legg, S.; Hedderley, D. The weight and use of schoolbags in New Zealand secondary schools. Ergonomics 2001, 44, 819-824. [CrossRef] [PubMed]

36. Viry, P.; Creveuil, C.; Marcelli, C. Nonspecific back pain in children. A search for associated factors in 14-year-old schoolchildren. Rev. Rhum. (Engl. Ed.) 1999, 66, 381-388. [PubMed]

37. Dianat, I.; Javadivala, Z.; Allahverdipour, H. School bag weight and the occurrence of shoulder, hand/wrist and low back symptoms among Iranian elementary schoolchildren. Health Promot. Perspect. 2011, 1, 76. [PubMed]

38. Dockrell, S.; Blake, C.; Simms, C. Guidelines for schoolbag carriage: An appraisal of safe load limits for schoolbag weight and duration of carriage. Work 2016, 53, 679-688. [CrossRef]

39. Azabagic, S.; Spahic, R.; Pranjic, N.; Mulic, M. Epidemiology of musculoskeletal disorders in primary school children in Bosnia and Herzegovina. Mater. Socio-Med. 2016, 28, 164. [CrossRef]

40. Aprile, I.; Di Stasio, E.; Vincenzi, M.T.; Arezzo, M.F.; De Santis, F.; Mosca, R.; Briani, C.; Di Sipio, E.; Germanotta, M.; Padua, L. The relationship between back pain and schoolbag use: A cross-sectional study of 5318 Italian students. Spine J. 2016, 16, 748-755. [CrossRef] 
41. Adeyemi, A.J.; Rohani, J.M.; Rani, M.A. Back pain arising from schoolbag usage among primary schoolchildren. Int. J. Ind. Ergon. 2014, 44, 590-600. [CrossRef]

42. Dianat, I.; Sorkhi, N.; Pourhossein, A.; Alipour, A.; Asghari-Jafarabadi, M. Neck, shoulder and low back pain in secondary schoolchildren in relation to schoolbag carriage: Should the recommended weight limits be gender-specific? Appl. Ergon. 2014, 45, 437-442. [CrossRef] 